\title{
Diyabetik Retinopati Teşhisi için Fundus Görüntülerinin Derin Öğrenme Tabanlı Sınıflandırılması
}

\author{
Yusuf Bahri Özçelik ${ }^{1}$, Aytaç Altan ${ }^{2 *}$ \\ ${ }^{1}$ Zonguldak Bülent Ecevit Üniversitesi, Mühendislik Fakültesi, Elektrik Elektronik Mühendisliği Bölümü, Zonguldak, Türkiye (ORCID: 0000-0001-6326-9398), \\ ybahri.ozcelik@fbe.karaelmas.edu.tr \\ $2^{2 *}$ Zonguldak Bülent Ecevit Üniversitesi, Mühendislik Fakültesi, Elektrik Elektronik Mühendisliği Bölümü, Zonguldak, Türkiye, (ORCID: 0000-0001-7923-4528), \\ aytacaltan@beun.edu.tr
}

(International Symposium on Multidisciplinary Studies and Innovative Technologies (ISMSIT) 2021 - 21-23 October 2021)

(DOI: 10.31590/ejosat.1011806)

ATIF/REFERENCE: Özçelik, Y. B. \& Altan, A. (2021). Diyabetik Retinopati Teşhisi için Fundus Görüntülerinin Derin Öğrenme Tabanlı Sinıflandırılması. Avrupa Bilim ve Teknoloji Dergisi, (29), 156-167.

Öz

Günümüzde en yaygın körlük nedenlerinden biri olan Diyabetik Retinopati (DR), gözün retina ağ tabakasında yer alan kan damarlarında diyabete bağlı olarak oluşan hasarlanmalardır. Hastaların görme yetisini kaybetmemesi için DR'nin erken teşhis ve tedavisi hayati önem taşımaktadır. Bu çalışmada, DR’nin erken teşhis ve tedavisi için fundus görüntüleri kullanılarak derin öğrenme tabanlı bir model geliştirilmiştir. Geliştirilen model iki aşamadan oluşmaktadır. İlk aşamada, modelin aşırı öğrenmesinin engellenebilmesi için fundus görüntülerine iki boyutlu sinyal işleme teknikleri uygulanmıştır. İkinci aşamada, derin öğrenme tekniklerinden Evrişimli Sinir Ağı (ESA) ve transfer öğrenmesi yöntemleri kullanılarak sınıflandırma modeli oluşturulmuştur. Modelin eğitiminde 5100 fundus görüntü verisi kullanılmıştır. Elde edilen model sağlıklı (DR yok), hafif Non-Proliferatif DR (NPDR), orta NPDR, şiddetli NPDR ve Proliferatif DR (PDR) gibi 5 sınıfı içeren 900 fundus görüntü verisi üzerinde test edilmiştir. Modelin sağlamlığı 10-kat çapraz doğrulama yöntemi kullanılarak doğrulanmıştır. Önerilen modelin sınıflandırma performansı \%97.8 olarak ölçülmüştür. Ayrıca, modelin sınıflandırma performansı literatürde yer alan üç model ile kıyaslanmıştır. Elde edilen sonuçlar, önerilen modelin, DR'yi teşhis etmek için çok etkili ve başarılı olduğunu göstermektedir.

Anahtar Kelimeler: Diyabetik retinopati, Derin öğrenme, Fundus, Sınıflandırma, Evrişimli sinir ağı, Transfer öğrenme.

\section{Deep Learning-based Classification of Fundus Images for the Diagnosis of Diabetic Retinopathy}

\begin{abstract}
Diabetic Retinopathy (DR), one of the most common causes of blindness today, is damage to the blood vessels in the retinal mesh layer of the eye due to diabetes. Early diagnosis and treatment of DR is vital so that patients do not lose their sight. In this study, a deep learning-based model is developed using fundus images for the early diagnosis and treatment of DR. The developed model consists of two stages. In the first stage, two-dimensional signal processing techniques are applied to the fundus images to prevent overfitting of the model. In the second stage, the classification model is created by using deep learning techniques, Convolutional Neural Network $(\mathrm{CNN})$ and transfer learning methods. 5100 fundus image data is used in the training of the model. The validity of the obtained model is tested on 900 fundus image data containing 5 classes such as No DR, mild Non-Proliferative DR (NPDR), moderate NPDR, severe NPDR and Proliferative DR (PDR). The robustness of the model is verified using the 10-fold cross validation method. The classification performance of the proposed model is measured as $97.8 \%$. Moreover, the classification performance of the model is compared with the three models in the literature. The obtained results show that the proposed model is very effective and successful for diagnosing DR.
\end{abstract}

Keywords: Diabetic retinopathy, Deep learning, Fundus, Classification, Convolutional neural network, Transfer learning.

\footnotetext{
* Sorumlu Yazar: aytacaltan@beun.edu.tr
} 


\section{Giriş}

Diyabet, pankreasın yeterli miktarda insülin hormonu üretememesi veya insülin hormonunu etkili bir şekilde kullanamamasından dolayı vücuttaki kan şekerinin artmasıyla ortaya çıkan ve yaşam boyu süren metabolik bir hastalıktır. 2019 yılında Dünya' da diyabeti olan kişi sayısı 463 milyon olarak tahmin edilmektedir ve bu sayının 2030 yilında 578 milyona ulaşması beklenmektedir (Saeedi et al. 2019). En yaygın körlük nedenlerinden biri olan Diyabetik Retinopati (DR), diyabete bağlı olarak retina ağ tabakasında yer alan kan damarlarında meydana gelen hasarlanmalardır. DR' nin toplum içerisinde görülme sıklığ 1 , diyabet süresine paralel olarak artmakta ve genel olarak diyabetlilerin \%30'unda görülmektedir (Klein Kobrin 2007). Bu durum diyabet hastalarının görme yetenekleri için büyük risk oluşturmaktadır. DR'nin erken aşamada teşhis edilerek tedavi edilmesi diyabet hastalarının görme yeteneklerini kaybetmelerini önlemek ve DR ilerlemesini yavaşlatmak için hayati önem taşımaktadır. $\mathrm{Bu}$ nedenle, diyabet hastalarının her yıl doktor gözetiminde taramadan geçmeleri gerekmektedir. Ancak, bu taramalar çok vakit almakta, iyi bir deneyim ve uzmanlık gerektirmektedir. $\mathrm{Bu}$ problemin üstesinden gelebilmek ve hekimlere yardımcı olabilmek için hızlı ve güvenilir bilgisayarlı otomatik tarama sistemlerinden faydalanmak günümüzde kaçınılmaz hale gelmiştir (Nazir et al. 2019).

DR hastalığ 1 , Non-Proliferatif DR (NPDR) ve Proliferatif DR (PDR) olmak üzere iki kategoride incelenmektedir. NPDR hastalığın erken evresi, PDR ise ileri evresi olarak tanımlanmaktadır. Hastalığın NPDR evresi, hafif, orta ve şiddetli olmak üzere üç sınıfa ayrılmaktadır. Hastalığın hafif NPDR evresinde, fundus görüntülerinde mikroanevrizmalar ve az sayıda küçük kanamalar görülmektedir. Hastalığın orta NPDR evresinde, fundus görüntülerinde retinal katmanın en az birinde yaygın şekilde artmış mikroanevrizmalar, kanamalar, eksudalar, venöz değişiklikler ve IntRaretinal Mikrovasküler Anomaliler (IRMA) gözlemlenmektedir. Hastalığın şiddetli NPDR evresinde ise fundus görüntülerinde baskın şekilde mikroanevrizmalar, kanamalar ve eksudalar ile birlikte yaygın arterioler tıkanıklıklar, venöz değişiklikler ve IRMA yoğunluğunda artışlar görülmektedir. Hastalığın PDR evresinde, NPDR evresindeki bulgulara ek olarak fundus görüntülerinde retinal neovaskülarizasyonlar ve minimal fibröz doku proliferasyonu bulgular1 tespit edilmektedir (Aiello 2003; Stratton et al. 2001). $\mathrm{Bu}$ bulgular hastaların görme yetilerinin azalmasına veya yok olmasına neden olmaktadır. Son yıllarda yapılan araştırmalar, görme yetisinin kaybedilmemesi için DR hastalığının erken safhada tespit edilmesi üzerine yoğunlaşmaktadır.

Nazir ve arkadaşları (Nazir et al. 2019) gerçekleştirdikleri çalışmalarında DR hastalığını sınıflandırmak için anatomik çıkarımlardan bağımsız yeni bir yöntem önermişlerdir. Önerilen yöntemde içerik tabanlı görüntü alma alanının araştırmasının özellik çıkarımı ve çok kategorili tanıma kavramlarını genişleterek yeni dört açılı yerel sekizli desenler (tetragonal local octa pattern-T-LOP) olarak adlandırdıkları yöntemle fundus görüntülerinden anatomik çıkarımlardan bağımsız özellik çıkarımı gerçekleştirmişlerdir. Sınıflandırma yöntemi olarak olarak aşırı öğrenme makinesi (Extreme Learning Machine-ELM) kullanmışlardır. 44000'den fazla DR hastasını temsil eden 88704 adet fundus görüntüsünden oluşan veri setini kullanarak gerçekleştirdikleri deneysel çalışmada ELM ile doğruluk, kesinlik ve geri çağırma sırasıyla \%99.6, \%99.1 ve \%99.3 olarak ölçülmüştür. Math ve Fatima (Math and Fatima 2021) tarafindan DR ve DR lezyonlarını tespit etmek ve sınıflandırmak için derin öğrenmeden faydalanılarak bölütleme tabanlı öğrenme yaklaşımı önerilmiştir. Tüm retina görüntüleri, farklı kontrast, görüntü çözünürlüğü ve aydınlatmaya sahip fundus görüntüleri ve kitle taramasından alınmıştır. Elde edilen görüntü verilerine ön işleme uygulanmıştır. Görüntü bölütleri önceden işlenmiş görüntü verilerinden çıkarılmış ve diyabetik retinopatinin bölüt seviyesi dikkate alınarak Evrişimli Sinir Ağı (Convolutional Neural Network-CNN) ile modellenmiştir. Düzensiz DR'nin lezyonunu daha iyi elde etmek için ise uçtan uca bölütleme tabanlı bir öğrenme yaklaşımı uygulanmıştır. Önerilen modelin başarımı yaklaşık olarak \%96.3 ölçülmüştür. Şentürk (Şentürk 2020) çalışmasında, DR tanısı için veri madenciliği aracı olan Rapid Miner kullanarak Yapay Sinir Ağı (Artificial Neural NetworkANN) temelli bir yöntem önermiştir. Önerilen yöntemde sınıflandırma için Messidor veri setindeki fundus görüntülerinin özellikleri ve Rapid Miner ANN modelinin özellikleri, sadece doğrusal sınıflandırma problemlerine değil aynı zamanda doğrusal olmayan ve düşük hesaplama maliyetine sahip çok sınıflı problemlere çözüm sağladığı için retinopatisi olan olası diyabetik hastaların sınıflandırılması için kullanılmıştır. Önerilen yöntemin duyarlılığ 1 ve doğruluğu sirasıyla $\% 88.5$ ve $\% 76.1$ olarak elde edilmiştir. Chakraborty ve arkadaşları (Chakraborty et al. 2020) tarafindan DR teşhisi için denetimli öğrenme tabanlı bir ANN modeli önerilmiştir. Çalışmada, girdi olarak UCI makine öğrenme deposundaki retina görüntülerinden çıkarılan öznitelikler kullanılmıştır. Elde edilen öznitelikler, denetimli öğrenme tabanlı ileri beslemeli-geri yayılımlı bir ANN mimarisine uygulanmıştır. Modelin başarımının yaklaşık olarak \%97.2 olduğu rapor edilmiştir. Khan ve arkadaşları (Khan et al. 2020) tarafindan DR tespiti için fundus görüntülerinin piksel değerlerini kullanan destek vektör makinesi (Support Vector Machine-SVM) tabanlı sınıflandırma modeli geliştirilmiştir. Sınırlı sayıdaki fundus görüntü verisi üzerinde test edilen modelin başarımı yaklaşık olarak \%90 ölçülmüştür. Vijayan ve arkadaşları (Vijayan et al. 2020) ise DR sınıflandırması için öznitelik çıkarımına dayalı bir makine öğrenmesi yöntemi önermişlerdir. Önerilen modelin ilk aşamasında, 35126 fundus görüntüsünden oluşan veri setindeki sınıfların görüntü sayılarının dengesizliğinin giderilmesi için rastgele oluşturucular ve rastgele alt örnek filtreleri kullanılmıştır. Modelin ikinci aşamasında, elde edilen görüntülerden Gabor filtresi kullanılarak toplam 61 öznitelik çıkarılmıştır. Son aşamasında, fundus görüntüleri J48, k- en yakın komşu (KNearest Neighbors-KNN), rastgele orman (Random Forest-RF) ve OneR sınıflandırıcıları kullanılarak sınıflandırılmıştır.

Deepa ve arkadaşları (Deepa et al. 2021) tarafindan DR tespiti için makro ve mikro öznitelik çıkarımına dayalı dört aşamadan oluşan aşırı öğrenme makinesi (Extreme Learning Machine-ELM) tabanlı model önerilmiştir. Önerilen modelin başarımı ANN ve KNN tabanlı sinıflandırıcı modellerin performansı ile kıyaslanmıştır. Önerilen sınıflandırıcı modelinin performansının yaklaşık olarak \%93.2 olduğu belirtilmiştir. Dhakal (Dhakal et al. 2019) tarafindan önerilen modelde öncelikle fundus görüntülerine histogram eşitleme tekniğinin uygulandığg belirtilmiştir. Elde edilen görüntülerden bölütleme ile optik disk, damarlar ve eksudalar çıkarılmıştır. Gri düzey birlikte oluşum matrisi ile öznitelikler çıkarılmıştır. Sınıflandırma işlemi Adaboost ve CNN ile gerçekleştirilmiştir. Adaboost ve CNN teknikleri ile oluşturulan modellerin başarımı MESSIDOR ve EyePACS standart veri setleri için sirasıyla \%73.9 ve \%80.9 olarak ölçülmüştür. 
DR hastalığının tespit edilebilmesi için birçok uygulamalı mühendislik ve uçtan uca öğrenme tabanlı yaklaşımlar kullanılmaktadır (Nida et al. 2019), ancak hiçbir yaklaşım DR hastalığının hafif NPDR evresini yüksek doğrulukla sınıflandıramamaktadır. Hafif NPDR evrenin tespit edilmesi bu ölümcül hastalığın erken tedavisi ve kontrolü için hayati önem taşımaktadır (Qummar et al. 2019, Gayathri et al. 2020). Bu çalışmada, DR hastalığının hafif NPDR evresi dahil olmak üzere tüm evrelerinin yüksek doğrulukla ve hızlı şekilde tespit edilebilmesi için iki boyutlu sinyal işleme teknikleri, CNN ve transfer öğrenmesi yöntemleri kullanılarak derin öğrenme tabanlı DR hastalığı sınıflandırıcı modeli önerilmektedir. Çalışmanın geri kalanı aşağıdaki şekilde organize edilmektedir. Çalışmanın ikinci bölümünde, DR hastalığının fundus görüntülerinden tanısı için önerilen metodoloji tanıtılmaktadır. Üçüncü bölümde, önerilen sınıflandırma modelinin deneysel sonuçları sunulmakta ve tartışılmaktadır. Son bölümde, çalışmanın sonuçları ve gelecek projeksiyonu vurgulanmaktadır.

\section{Diyabetik Retinopati Hastalığının Teşhisi ve Sinıflandırılması}

Bu bölümde, göz ve retinanın yapısı, DR hastalığının erken evrede teşhisinin önemi ile birlikte DR hastalığının tanısı için önerilen modelde dahil olmak üzere çalışmada kullanılan derin öğrenme mimari yapıları ve algoritmaları tanıtılmaktadır.

\subsection{Retina Yapısı ve DR Hastalığı}

Çeşitli mesafelerde bulunan nesnelerin renk ve biçim bilgilerini algılayarak insanın dış dünya ile etkileşimini sağlayan göz, yaklaşık olarak 2-2.5 cm çapında ve ortalama 10-12 gram ağırlığında küresel bir yapıya sahiptir. Dıştan içe doğru sert tabaka, damar tabaka ve retina tabaka olmak üzere temelde üç tabakadan oluşan insan gözünün anatomisi Şekil 1'de görülmektedir (Willoughby et al. 2010).

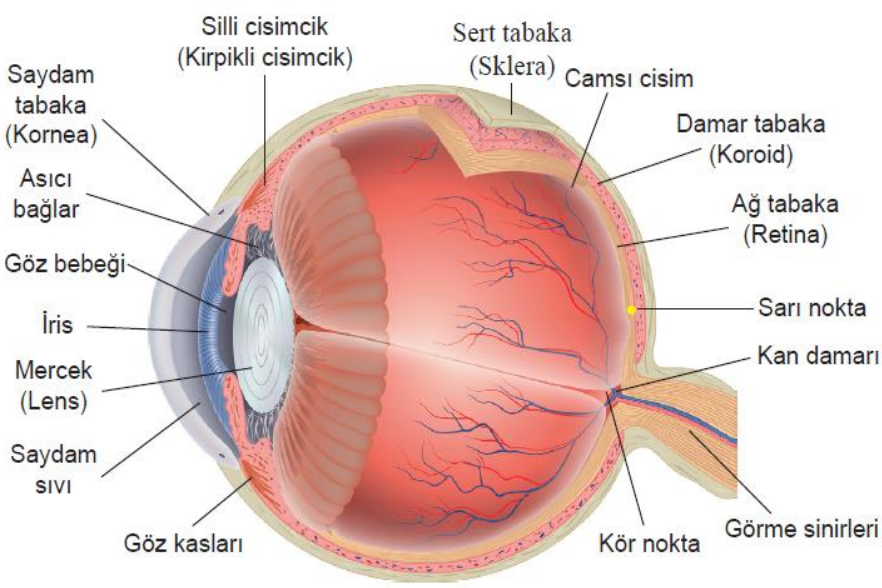

Şekil 1. Insan gözü anatomisi.

Gözün en dış kısmında bulunan sert tabaka, göze gelen ışınların ilk defa kırıldığı bölgedir. Bu tabaka, gözün içi ile dışı arasında koruyucu bir görev yapar. Sert tabakanın iç kısmında bulunan damar tabaka retinanın kanlanması ve beslenmesini sağlar. Göz küresinin iç yüzeyini kaplayan retina tabaka ise, görme işleminin gerçekleştiği bölümdür. Retina tabakasında renge ve ışı̆̆a duyarlı sinir hücreleri bulunmaktadır. Bu hücreler retina üzerine kırılarak gelen 1 şı̆̆ı elektriksel sinyallere dönüştürmekte ve merkezi sinir sistemine iletilebilmesi için optik sinire aktarmaktadır. Merkezi sinir sistemine iletilen sinyaller ile görüntü algılanmaktadır (Willoughby et al. 2010; Grossniklaus et al. 2015).

Optik sinirlerin sert tabakayı delerek geçtiği retinanın merkezinde bulunan bölüm optik disk olarak tanımlanmaktadır. Bu bölüm 1şığa duyarlı hücreler içermediği için 'kör nokta' olarak da adlandırılmaktadır (İnan 2014). Retinanın ortasına doğru olan kısımda makula yer alır. 4-5 mm çapına sahip olan makulanın merkezinde fovea bulunmaktadır. Sarımtırak renkli bir pigment içermesinden dolayı 'sarı nokta' olarak da adlandırılan foveada keskin görme sağlanmaktadır (Hood et al. 2013). Retina'nın temel yapısı Şekil 2'de gösterilmektedir. Retina yapısının bozulması, görme fonksiyonlarında retina yırtığı, retina dekolmanı, sarı nokta hastalığı, retinal ven ve retinal arter tıkanıklıkları, epiretinal membran, makula deliği, göz travmaları ve şeker hastalığına bağlı olarak gelişen DR gibi bazı problemleri beraberinde getirebilmektedir (La Cour and Friis 2002). Retinada görülen hastalıkların en önemlilerinden biri hiç şüphesiz şeker hastalığına bağlı gelişen DR'dir. DR hastalığı tedavi edilmediğinde, ilerleyen süreçte kişide kalıcı körlük durumuna sebep olabilmektedir. Bu nedenle DR' nin teşhis ve tedavisinin erken safhada yapılabilmesi önem arz etmektedir (Kramer et al. 2011).

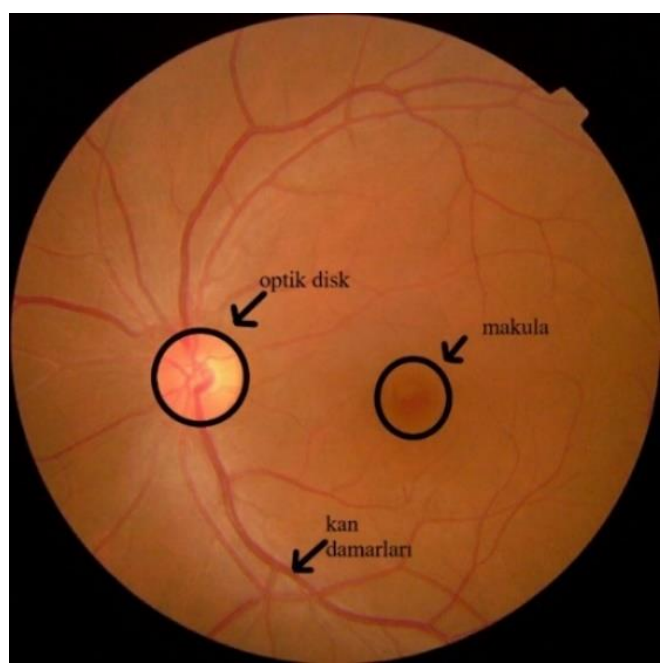

Şekil 2. Retina temel yaptst.

DR hastalığının görülme olasılığı dikkate alındığında diyabet hastalarının her yıl düzenli olarak retina taramasından geçmeleri gerekmektedir. Günümüzde, retina taramalarında yaygın biçimde Fundus Floresein Anjiyografisi (FFA) tekniği kullanılmaktadır. Retina hastalıklarına karşı kan damarlarının incelenmesi için sıklıkla kullanılan bu yöntemde, mavi ışık altında floresans veren sar1-turuncu renkli floresein adlı madde insan vücuduna koldan verilrek damarsal görüntüler elde edilmektedir. Bu teknikte DR teşhisi deneyimli ve uzman bir hekim tarafından FFA görüntüleri incelenerek konulabilmektedir (Antcliff et al. 2000). DR hastalığının erken evrelerinde hem hastalığın belirti göstermemesi hem de insan kaynaklı FFA inceleme hatalarından dolayı hastalara erken aşamada DR teşhisi konulamayabilmektedir. Bu durum, hastalığın hızla ilerlemesine yol açmakta ve tedavi sürecini zorlaştırmaktadır (Qummar et al. 2019).

\subsection{Fundus Görüntülerinden DR Hastalığının Teşhisi ve Sınıflandırma Metodolojisi}

$\mathrm{Bu}$ bölümde, DR hastalığının teşhisi ve evrelerinin sınıflandırılması için fundus görüntülerinden oluşan veri seti ile geliştirilen modelin çerçevesi tanıtılmaktadır. DR hastalığının sınıflandırılması için önerilen çerçevenin içeriği; fundus 
görüntülerinin ön işlenmesi, önerilen $\mathrm{CNN}$ algoritmasının eğitim aşaması ve elde edilen modelin test için ayrılan fundus görüntü veri kümesi üzerinde test edilme aşamasından oluşmaktadır. Önerilen modelin ön işleme aşamasında, fundus görüntülerinin boyutlandırılması, normalizasyonu ve görüntü işleme teknikleri ile veri artırma işlemleri yapılmaktadır. Ön işleme tabi tutulan fundus görüntüleri kullanılarak VGG-19 mimarisine sahip CNN algoritması ile modelin eğitimi gerçekleştirilmektedir. Fundus görüntülerinden oluşan veri setinin \%70'i öznitelik matrislerinin oluşturulması, özniteliklerin seçimi ve fundus görüntülerinin sınıflandırılması için önerilen modelin eğitimi için kullanılmaktadır. Veri setinin geri kalan \%30'luk kısmının yarısı modelin geçerliliği diğer yarısı ise modelin performansının test edilmesi için kullanılmaktadır. Modelin performansı doğruluk, kesinlik, geri çağırma, F1-skoru gibi sınıflandırma performans metrikleri ile ölçülmektedir. DR hastalığının teşhisi ve sınıflandırılması için önerilen modelin akış şeması Şekil 3'te sunulmaktadir.

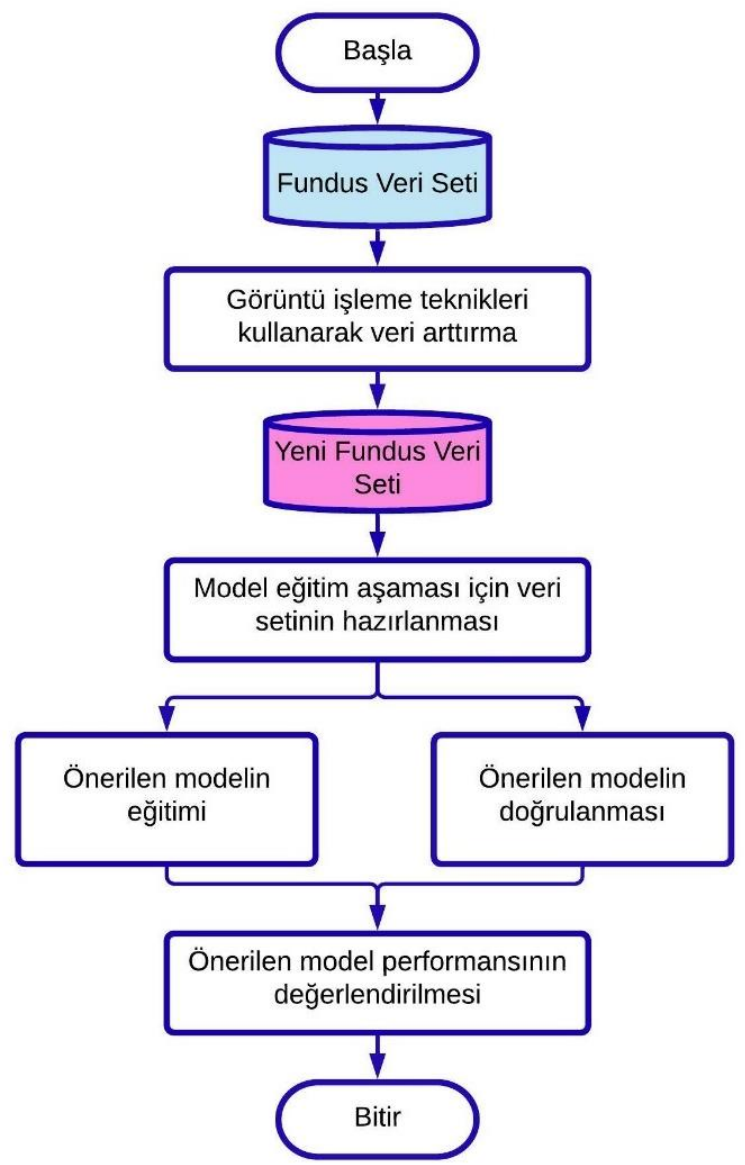

Şekil 3. DR hastalığının teşhisi için önerilen modelin akış şeması.

\subsection{Derin Öğrenme ve Evrişimli Sinir Ağı}

Derin öğrenme, insan beyni ile etkileşim halinde olan sinir hücrelerine benzetilerek tasarlanmış ve çok büyük miktarda etiketlenmiş verilerden özellikleri tespit edebilen sistemler oluşturmak için birden fazla art arda katmandan oluşan derin sinir ağlarının kullanıldığı bir yapay zekâ yöntemidir (Chan et al. 2015). Derin öğrenmenin temelinde çok katmanlı yapay sinir ağları yer almaktadır. Katmanların oluşturulması için birden fazla nöron bir araya gelmektedir. Oluşturulan katmanların birbiri ardına sıralanmasıyla oluşan yapay sinir ağı Derin Sinir A ̆ğ (DSA) olarak da adlandırılmaktadır. Buradaki derin ifadesi oluşturulan ağdaki katman sayısını işaret etmektedir. Katman sayısı arttıkça ağ yapısı derinleşmektedir. Klasik yapay sinir ağları iki veya üç katmandan meydana gelirken DSA yüzlerce katmandan meydana gelebilmektedir. Veri kümeleri bu katmanlardan geçirildiğinde DSA, verilerin sınıflandırılması için özniteliklerin hesaplanmasına yardımcı olmaktadır. Katmanları oluşturan nöronların optimum ağırlık matrisleri, kayıp fonksiyon değerini minimize etmek için optimizasyon algoritması kullanılarak hesaplanmaktadır. DSA'nın eğitilmesi belirli sayıda epok ile gerçekleştirilmekte ve her epoktan sonra nöronların ağırlıkları güncellenerek kayıp fonksiyonu değerinin azalarak sifira doğru gitmesi sağlanmaktadır.

CNN, bir girdi ve bir çıktı katmanının birden fazla gizli katman ile birlikte kullanılmasından oluşan genel bir yapay sinir ağı modelidir. Modele sunulan giriş verisi bir nöron tarafindan alınır ve katmanlarda bazı fonksiyonlara tabi tutularak çıkış verisine ulaşılır (Indolia et al. 2018). Genel olarak CNN,

$$
F(X, W)=Y
$$

ile ifade edilmektedir. Burada, $X$ vektörel olarak giriş verisini $Y$ ise çıkış vektörünü temsil etmektedir. İki bitişik katmanın nöronları arasındaki bağlantının ağırlık vektörü $W$ ile gösterilmektedir. Ağırlık vektörü bağlantının gücünü temsil etmek için kullanılmaktadır. Sınıflandırma işlemi bu ağırlık vektörü ile gerçekleştirilmektedir. CNN, ağırlık vektörü yardımı ile elde edilen bağlamsal bilgi doğrultusunda verileri sinıflandırabilme yeteneği ile sinıflandırma problemlerinde sıklıkla tercih edilmektedir (Han et al. 2018). Çalışmada önerilen CNN modeli VGG-19 mimarisi ile oluşturulmaktadır.

CNN, evrişim katmanı, havuzlama katmanı, aktivasyon katmanı ve tam bağlantı katmanı olmak üzere dört katmandan oluşmaktadır. Evrişim işlemi, görüntü piksellerinin üzerinde kaydırılarak uygulanan filtreler ile gerçekleştirilmektedir. Filtreler, görüntüdeki piksel değerleriyle çarpılan bir ağırlık matrisidir. İki boyutlu bir evrişim işlemi Şekil 4'de gösterilmektedir.

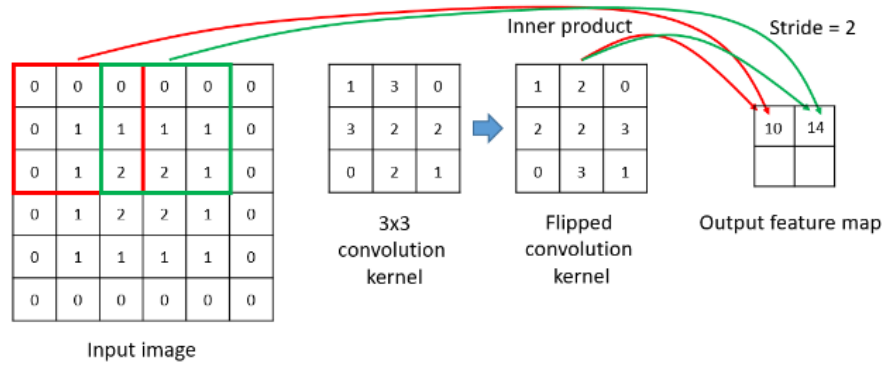

Şekil 4. Iki boyutlu evrişim işlemi.

CNN'lerde evrişim katmanının ard arda olması, görüntünün özellik haritalarını çıkarmakta ve görüntüdeki karmaşık desenleri çözümlemektedir. Evrişimli katmanlardan çıkan özellik haritaları, bir aktivasyon fonksiyonuyla beslenmektedir. $\mathrm{Bu}$ fonksiyon genelde doğrultulmuş doğrusal birim olarak bilinen ReLu (Rectified Linear Unit-ReLu) aktivasyon fonksiyonu olarak tanımlanmaktadır. Havuzlama katmanları, evrişimli katmandan gelen özellik haritalarındaki temel bilgileri koruyarak haritaların boyutlarının azaltılmasını sağlamaktadır (Hossin and Sulaiman 2015). Havuzlama işlemi Şekil 5'te sunulmaktadır. Bu işlem ile parametrelerin sayısı dolayısıyla yapılacak olan işlemin hesaplama maliyeti azaltılmaktadır. 


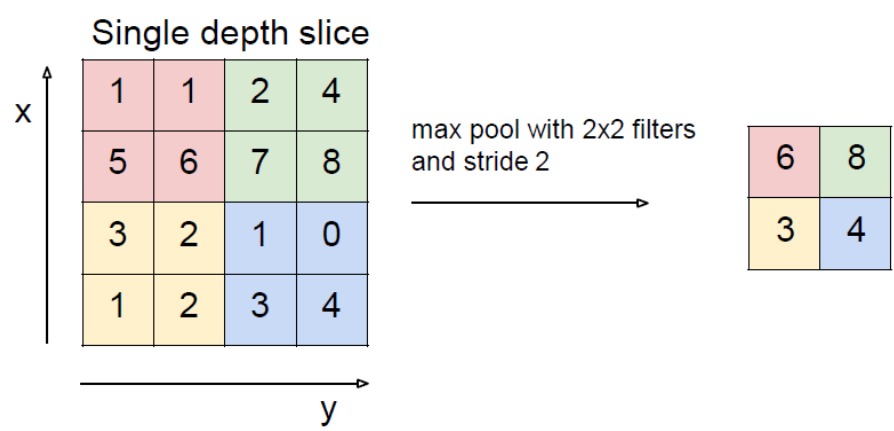

Şekil 5. Havuzlama işlemi.

\subsubsection{Transfer Öğrenme}

Transfer öğrenme, derin öğrenmede sıklıkla kullanılan bir tekniktir. $\mathrm{Bu}$ yöntem tüm modelin sıfırdan inşa edilemediği durumlarda oldukça faydalıdır. Transfer öğrenmenin temelinde, büyük bir veri kümesi üzerinde büyük ölçekli görüntü sınıflandırma görevinde eğitilmiş modeli kullanma ve bilgilerini küçük bir veri kümesine aktarma işlemi yer almaktadır. Buradaki düşünce önceden eğitilmiş modelin ağırlıklarını kullanarak küçük veri kümesinin özniteliklerini çıkarmak ve model parametrelerini hassas şekilde ayarlamaktır (Khan et al. 2019). Bu nedenle çalışmada daha önce ImageNet veri seti (Russakovsky et al. 2015) ile eğitilmiş VGG-19 ağ ile oluşturulan bir model önerilmektedir. Önerilen modelin performansı ImageNet veri seti ile eğitilmiş Xception, InceptionV3 ve Resnet101 mimarileri ile oluşturulmuş üç modelin performansı ile kıyaslanmaktadır.

VGG-19: Görsel Geometri Grup Ağ1 (Visual Geometry Group Network-VGGNet), Simonyan ve Zisserman tarafindan ortaya konulan çok katmanlı bir derin sinir ağıdır. Çalışmada önerilen VGG-19 mimarisi 16 evrişim katmanı ve 3 tam bağlantılı katman olmak üzere toplam 19 katmandan oluşmaktadır. Mimari, derinlik seviyesinin artması için adım aralığı 1 olan $3 \times 3$ boyutunda evrişimli katmanlar içerdiği için oldukça kullanışlıdır. ReLu aktivasyon fonksiyonu ile her evrişimli katmandan sonra modelin sınıflandırma performansı iyileştirilmekte ve hesaplama süresi en aza indirilmektedir. Özniteliklerin boyutunun azaltılabilmesi için beş adet maksimum havuzlama katmanı kullanılmaktadır (Simonyan and Zisserman 2014).

$\mathrm{Bu}$ çalışmada düşük hesaplama maliyeti, kullanılabilirlik, yüksek hız ve yüksek doğruluk dikkate alınarak Şekil 6'da gösterilen VGG-19 mimarisi kullanılmaktadır. VGG-19 temel ağının blok evrişim katmanlarının ardına sırasıyla 512, 256 ve 5 nöronlu üç adet tam bağlantılı katman eklenmektedir. Ayrıca, 512 ve 256 nöronlu tam bağlantılı katmanlara sirasıyla 0.01 ve 0.1 oranında kernel regülarizasyonu uygulanmaktadır. Elde edilen modelin aşırı öğrenmesinin önüne geçilebilmesi için 0.2 oranında iletim sönümü katmanı kullanılmaktadır.

Xception: Xception, Keras üreticisi Francaois Chollet tarafından önerilen bir mimaridir. Çok sayıda katman ve derin ayrılabilir evrişimli katmanlar içermektedir (Chollet 2017).

InceptionV3: Szegedy ve arkadaşları tarafindan V2 ve V1 modelleriyle birlikte önerilen InceptionV3, temelinde $\mathrm{CNN}$ algoritmasına dayanmaktadır. Diğer V2 ve V1 modellerinden farkı evrişim katmanlarına ek olarak yardımcı sınıflayıcı küme normalizasyonu ve tam bağlantılı katmanlara sahiptir (Szegedy et al. 2016).

ResNet101: 101 katman derinliğinde $\mathrm{CNN}$ tabanlı bir mimari olan ResNet101, ImageNet veri seti ile önceden eğitilmektedir. Geniş bir görüntü yelpazesine sahip olan ağ, 1000 nesneyi kategorilerine ayırabilmektedir (He et al. 2016).

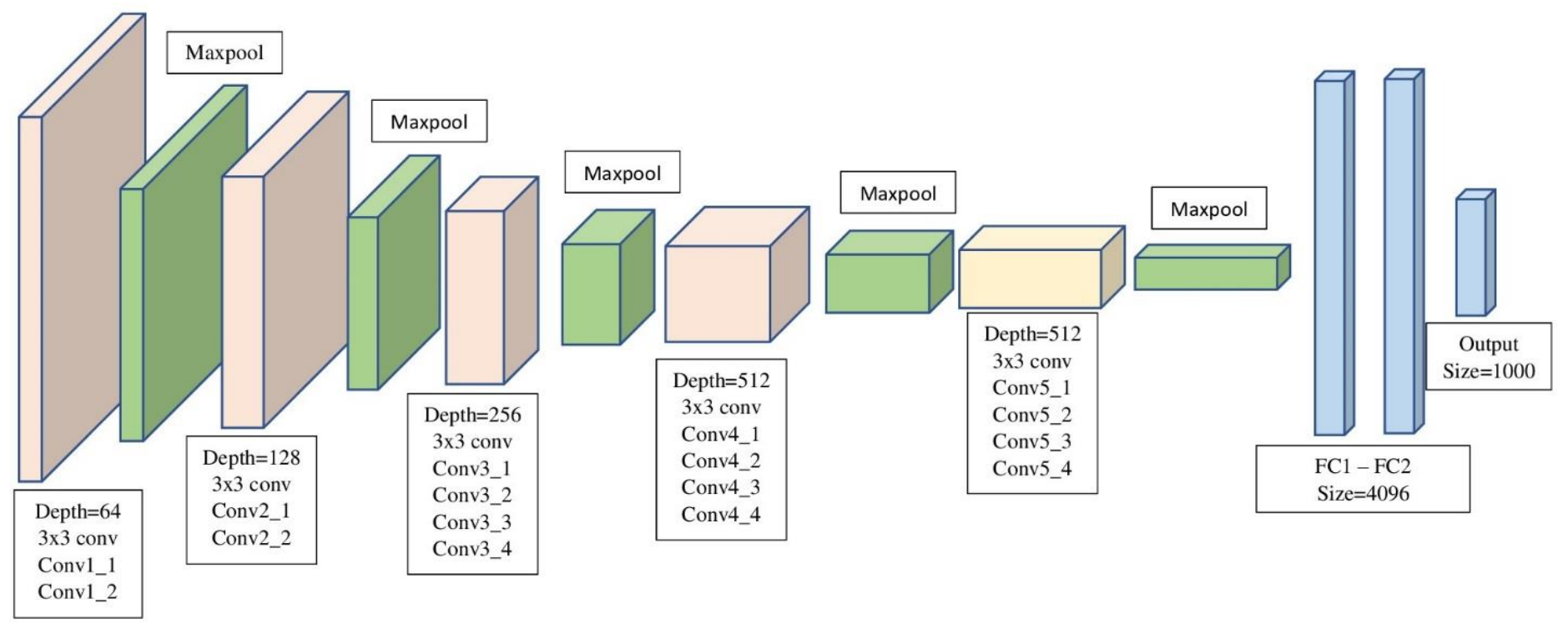

Şekil 6. Önerilen modelde kullanlan VGG-19 mimarisi.

\section{Araştırma Sonuçları ve Tartışma}

Bu bölümde, DR hastalığının "DR yok, Hafif NPDR, Orta NPDR, Şiddetli NPDR ve PDR" şeklinde sınıflandırılarak teşhis 
edilebilmesi için önerilen VGG-19 modelinin sınıflandırma performansı belirlenmesine yönelik çalışmalar yer almaktadır. Çalışmada her bir sınıf için 1200 olmak üzere toplam 6000 fundus görüntüsü kullanılmaktadır. Önerilen modelin performansının ölçülmesinde kullanılan hata metrikleri tanımlanmaktadır. Önerilen modelin başarımı Xception, InceptionV3 ve ResNet101 modelleri ile elde edilen sonuçlar ile kıyaslanmaktadır.

\subsection{DR Veri Seti}

Çalışmada, Asya Pasifik Tele-Oftalmoloji Derneği (Asia Pacific Tele-Ophthalmology Society-APTOS) tarafindan düzenlenen DR sınıflandırma yarışması için deneysel olarak elde edilerek hazırlanan veri seti kullanılmaktadır (APTOS 2019). Fundus görüntülerinden oluşan veri seti, Hindistan'daki Aravind Göz Hastanesi teknikerleri tarafından fundus fotoğrafçılığ kullanılarak çeşitli görüntüleme koşulları altında birden fazla klinikten toplanan toplam 3662 retina görüntüsünden oluşmaktadır. Veri setinde .png formatında yer alan retina görüntülerinin çözünürlüğü $474 \times 358$ ile $3388 \times 2588$ piksel arasında değişmektedir. Fundus görüntülerinden oluşan veri setinde, 1805 adet "DR Yok", 370 adet "Hafif NPDR", 999 adet "Orta NPDR", 193 adet "Şiddetli NPDR" ve 295 adet "PDR" sınıfına ait retina görüntüleri yer almaktadır. Veri seti incelediğinde, sınıflara ait görüntülerin sayısındaki dengesizlik dikkati çekmektedir. Model başarımının ve sağlamlılığının iyileştirilebilmesi için her bir sınıftan 193 adet olmak üzere toplam 965 retina görüntüsünden oluşan veri setine boyutlandırma, normalizasyon ve veri artırma teknikleri uygulanarak veri setindeki retina görüntüleri, görüntü ön işleme aşamasından geçirilmekte ve her bir sınıf için 1200 retina görüntüsünden oluşan fundus veri setine genişletilmektedir. Çalışmada kullanılan veri setinde her bir sınıf için 1007 adet sentetik ve 193 adet gerçek retina görüntüsü yer almaktadır. Genişletilen veri seti ile veri çeşitliliğinin sağlanması ve oluşturulan modelin aşırı öğrenmesinin önüne geçilmesi amaçlanmaktadır. Çalışmada kullanılan fundus veri setindeki "DR Yok, Hafif NPDR, Orta NPDR, Şiddetli NPDR ve PDR" sınıflarına ait retina görüntülerinin enine kesiti Şekil 7'de sunulmaktadir.
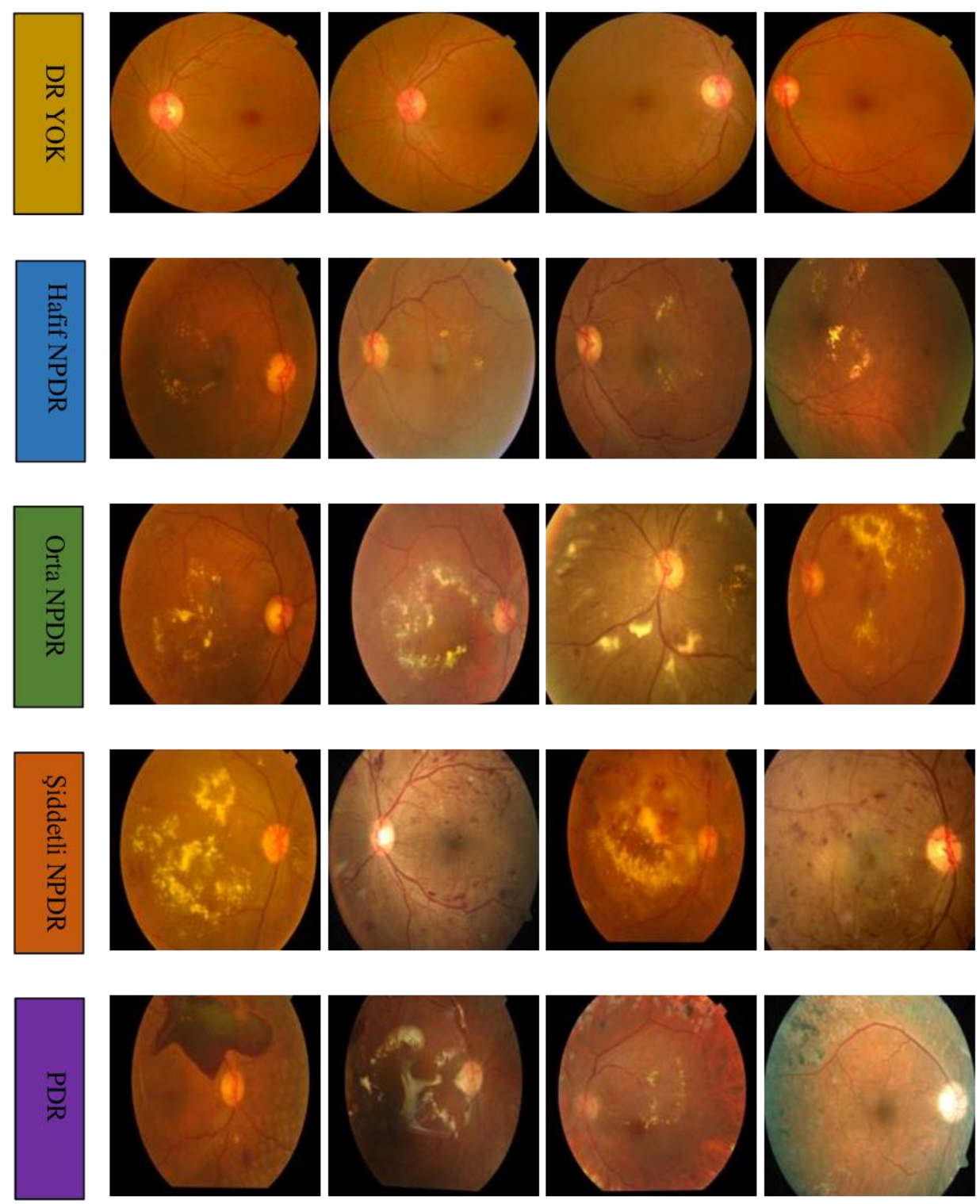

Şekil 7. DR hastalı̆̆ının “DR Yok, Hafif NPDR, Orta NPDR, Şiddetli NPDR ve PDR” evrelerine örnek fundus görüntüleri.

\subsection{Performans Metrikleri}


Karışıklık matrisi, gerçek pozitif (True Positive-TP), gerçek negatif (True Negative-TN), yanlış pozitif (False Positive-FP) ve yanlış negatif (False Negative-FN) terimlerinden oluşan bir matristir. TP, gerçek ve tahmini değerin 1 olduğu örnekleri temsil etmektedir. TN, gerçek ve tahmini değerin 0 olduğu örnekleri ifade etmektedir. FP, gerçek değerin 0 , tahmini değerin 1 olduğu örnekleri göstermektedir. FN ise gerçek değerin 1, tahmini değerin 0 olduğu örnekleri belirtmektedir. Çalışmada oluşturulan DR hastalığ değerlendirilmesinde kullanılanılan ve karışıklık matrisine göre hesaplanan performans metrikleri

$$
\begin{aligned}
& \operatorname{Doğruluk}(\text { Acc })=\frac{T P+T N}{T P+T N+F P+F N} \\
& \operatorname{Kesinlik}(\text { Prec })=\frac{T P}{T P+F P}
\end{aligned}
$$

Geri Çă̆ırma $(R e c)=\frac{T P}{T P+F N}$

$$
F 1-\text { skoru }=\frac{2 \times \operatorname{Rec} \times \text { Prec }}{\text { Rec }+ \text { Prec }}
$$

ile ifade edilmektedir. DR hastalığının teşhisi için önerilen modelin ve çalışmada kullanılan diğer modellerin performansları doğruluk, kesinlik, geri çağırma, F1-skoru gibi sınıflandırma performans metrikleri ile ölçülmektedir.

Doğruluk oranı, sınıflandırıcının ne sıklıkla doğru tahmin ettiğinin bir ölçüsüdür. Kesinlik, pozitif sınıfa ait olan ve pozitif sınıfa atanan örneklerin oranını ifade etmektedir. Geri çağırma, pozitif olarak tahmin edilmesi gereken değerlerin ne kadarının pozitif olarak tahmin edildiğini belirtmektedir. F1-skoru, hem geri çağırma hem de kesinlik endişelerini aynı anda tek bir sayıda dengeleyen tek bir skor sağlamaktadır.

\subsection{Deneysel Sonuçlar ve Tartışma}

Önceden eğitilmiş bir derin öğrenme modeli olan VGG-19 modeli, girişte en az $32 \times 32$ piksel boyutlu, en fazla $224 \times 224$ piksel boyutlu görüntü almaktadır. Görüntünün boyutu arttıkça kullanılan bilgisayarın RAM'i üzerindeki hesaplama yükü de artmaktadır. $\mathrm{Bu}$ nedenle, fundus görüntüleri üzerinde $150 \times$ 150 piksel boyutunda ölçeklendirme yapılmaktadır. Modelin eğitimi esnasında, Adam optimizasyon tekniği kullanılarak dönem (epok) başına öğrenme güncellenmektedir. Önerilen modelde learning rate, batch size ve epok değerleri sirasıyla $10^{-5}$, 32 ve 100 olarak ayarlanmaktadır. Modelin eğitiminde veri setinin \%70'i kullanılmaktadır. Veri setinin geri kalan \%30'luk kısmının yarısı ile modelin geçerliliği test edilmektedir. Model, 10 kat çapraz doğrulama yöntemi ile doğrulanmaktadır.

Fundus görüntülerine yönelik tüm deneyler, Intel Core i710875H işlemci, 8 GB NVIDIA GeForce RTX 3070 grafik kartı ve 16 GB RAM'e sahip kişisel bilgisayarda gerçekleştirilmiştir. Tüm kodlar MATLAB 2020b ile derlenmiştir. Önerilen modelin eğitim aşamasındaki hataların epoklara göre değişimi Şekil 8'de gösterilmektedir. Her epok için modelin eğitim ve geçerlilik aşamasındaki hatanın birbirine yakın olduğu görülmektedir. $\mathrm{Bu}$ durum modelin aşırı öğrenme durumuna düşmediğini garanti etmektedir. Önerilen model içerisinde yer alan $L 2$ düzenleyici ve seyreltme katmanının modelin aşırı öğrenmesini engellediği Şekil 8 yardımıyla doğrulanmaktadır. Önerilen modelin eğitim süresi epok başına ortalama 2.1 dakikadır. Modelin toplam eğitimi yaklaşık 3.5 saatte tamamlanmıştır. Önerilen model ile birlikte çalışmada kullanılan Xception, InceptionV3 ve ResNet101 modellerinin her bir epok değeri için test başarımları Şekil 9'da sunulmuştur. Önerilen modelin test başarımının diğer modellere kıyasla yüksek olduğu görülmektedir.

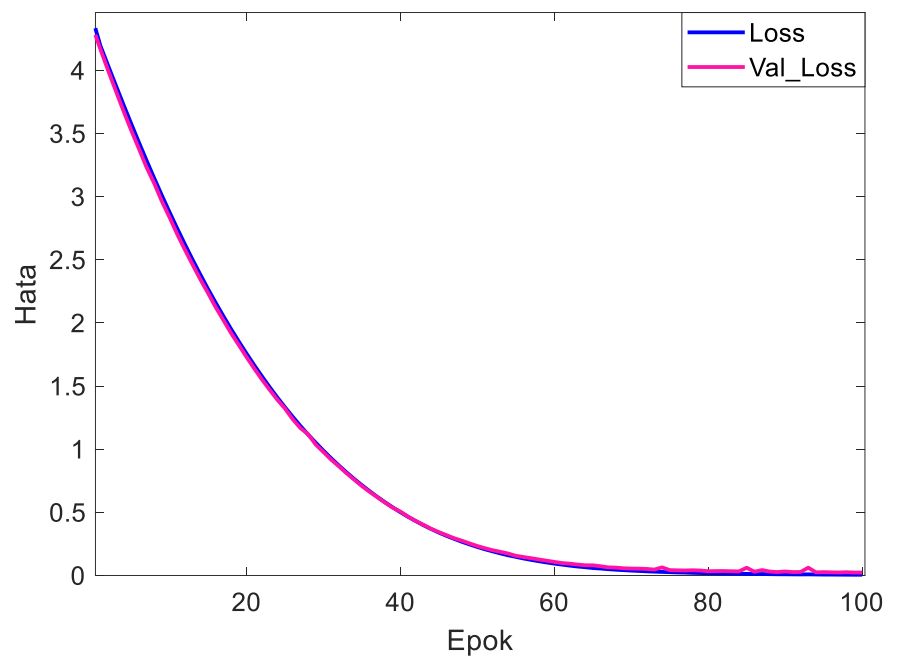

Şekil 8. Önerilen modelin kayıp fonksiyonunun her bir epok değerine göre değişimi.

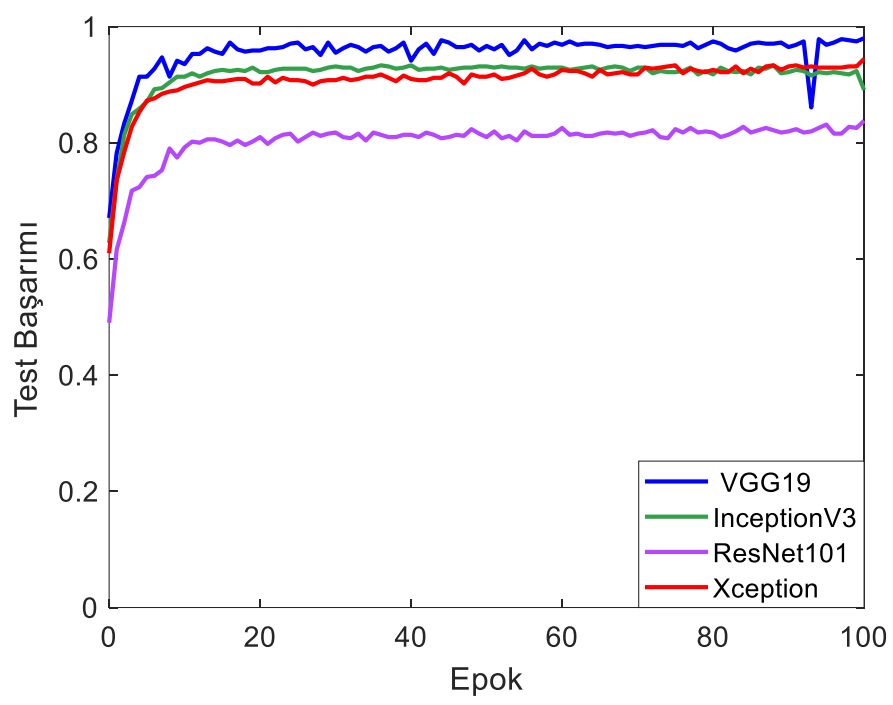

Şekil 9. Çalışmada kullanılan modellerin her bir epok değerine göre test başarımlart.

Çalışmada bahsedilen InceptionV3, Xception, ResNet101 modelleri ile birlikte önerilen DR sinıflandırma modelinin "DR Yok, Hafif NPDR, Orta NPDR, Şiddetli NPDR ve PDR" sınıflandırmasındaki karışıklık matrisi sırasıyla Şekil 10-13'te gösterilmiştir. Çalışmada bahsedilen dört DR teşhis modeli için elde edilen karışıklık matrisleri ve test başarım grafikleri birlikte değerlendirildiğinde, önerilen VGG-19 mimarisine sahip derin öğrenme modelinin sınıflandırma performansının diğer modellere kıyasla oldukça yüksek olduğu görülmektedir. 


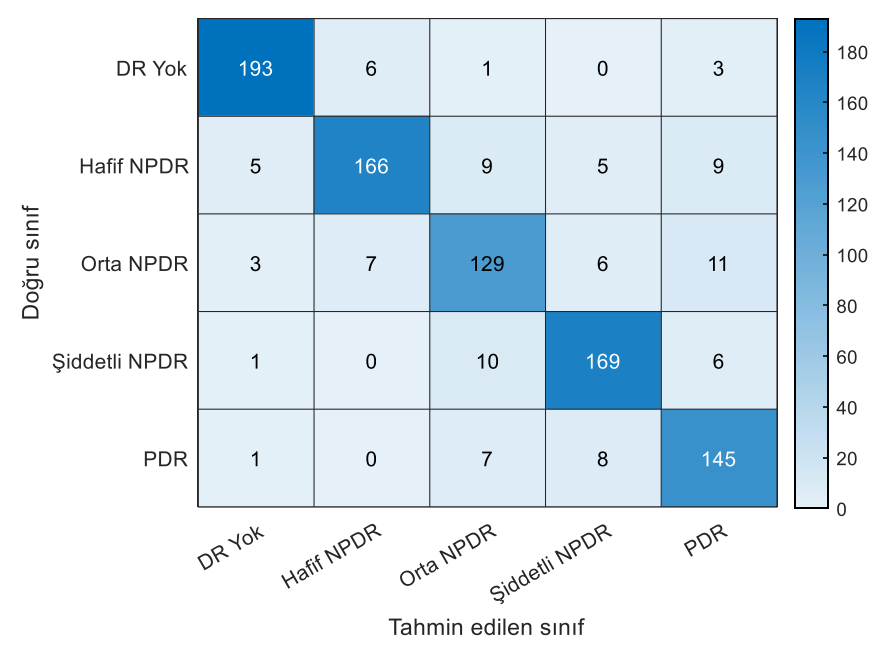

Şekil 10. InceptionV3 modeli ile DR sınıflandırması için elde edilen karışıklık matrisi.

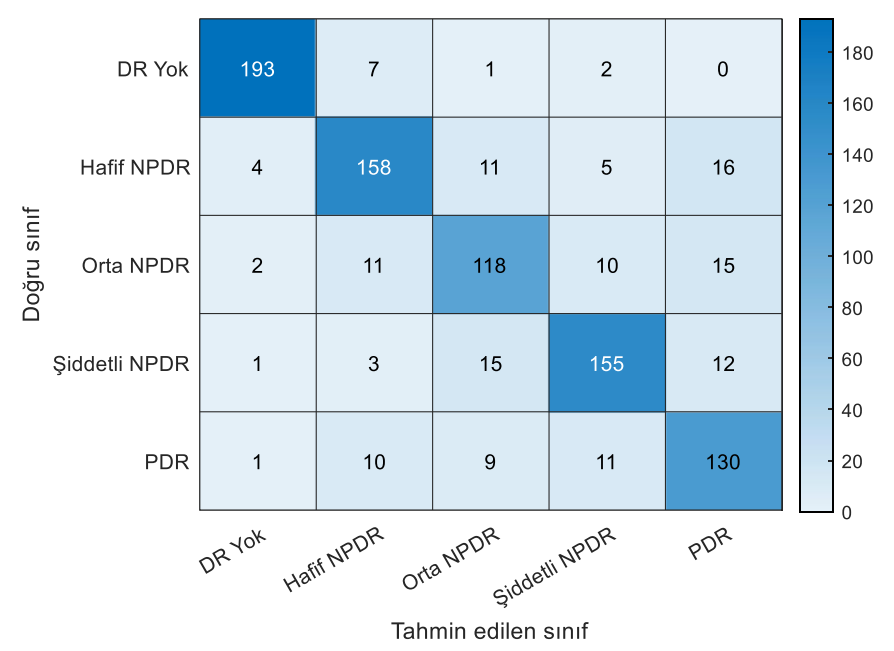

Şekil 12. ResNet101 modeli ile DR sınıflandırması için elde edilen karışıklık matrisi.

Doğruluk, kesinlik, geri çağırma ve F1-skoru performans ölçütlerine göre önerilen model ile birlikte Xception, InceptionV3, ResNet 101 modellerinin her bir kat için başarımları sırasıyla Tablo 1-4'de verilmiştir. Tablo 1 incelendiğinde, VGG19 mimarisinin beşinci katmanına kadar olan ağırlıkların kullanılmasının önerilen DR teşhis modelinin performansının iyileştirilmesinde belirgin şekilde etkili olduğu görülmüştür. Ayrıca, belirtilen performans ölçütleri dikkate alındığında önerilen modelin DR hastalığı sınıflandırma başarımının belirtilen diğer modellere kıyasla oldukça üstün olduğu gözlemlenmiştir.

ResNet101 modelinin her bir kat için doğruluk, kesinlik, geri çağırma ve F1-skoru performans ölçütleri Tablo 4'de verilmiştir. ResNet101 modelinin tüm katlar için ortalama doğruluk, kesinlik, geri çağırma ve F1-skoru değerleri sırasıyla \%84.9, \%84.5, \%84.5 ve \%84.4 olarak ölçülmüştür. Tablo 4 incelendiğinde, modelin belirtilen ölçütlere göre performansının yaklaşık olarak \%85 olduğu görülmektedir. InceptionV3 modelinin tüm katlar için ortalama doğruluk, kesinlik, geri çağırma ve F1-skoru değerleri sırasıyla \%88.5, \%88.2, \%88.2 ve \%88.1 olarak ölçülmüştür.

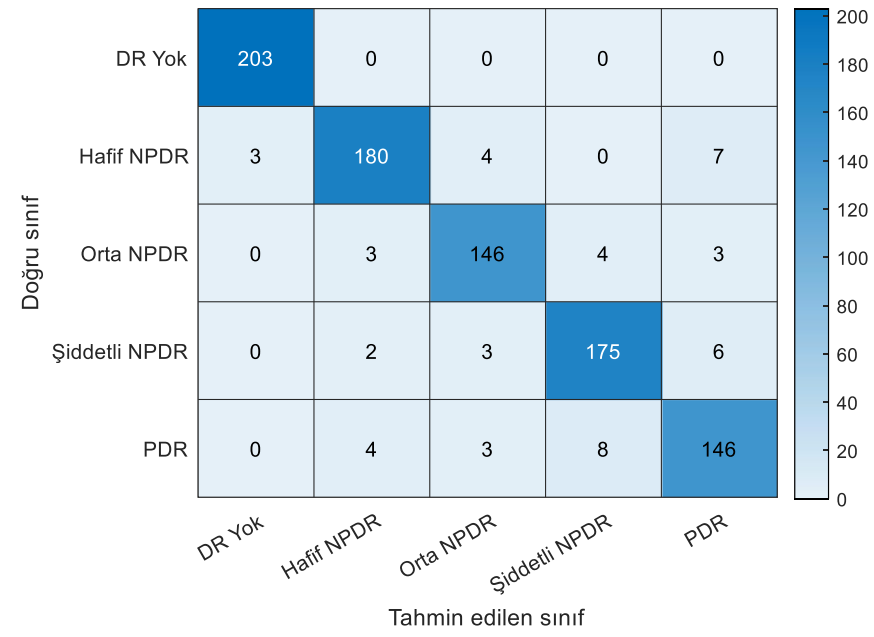

Şekil 11. Xception modeli ile DR sınıflandırması için elde edilen karışıklık matrisi.

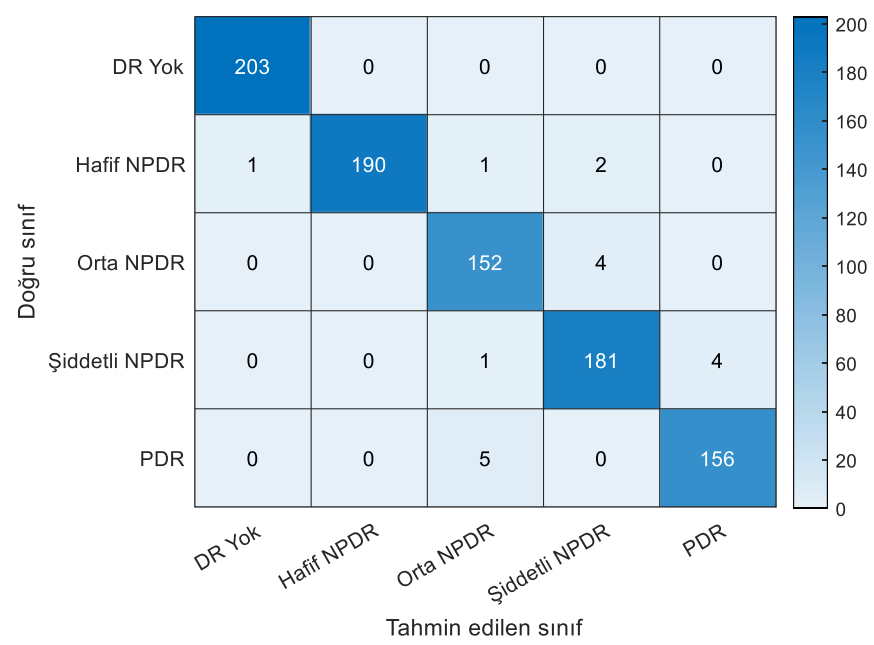

Şekil 13. VGG-19 modeli ile DR sinıflandırmast için elde edilen karışıklık matrisi.

Tablo 3 incelendiğinde, modelin belirtilen ölçütlere göre performansının yaklaşık olarak \%88 olduğu görülmektedir. Xception modelinin tüm katlar için ortalama doğruluk, kesinlik, geri çağırma ve F1-skoru değerleri sırasıyla \%95.4, \%95.2, \%95.2 ve $\% 95.1$ olarak ölçülmüștür. Tablo 2 incelendiğinde, modelin belirtilen ölçütlere göre performansının yaklaşık olarak \%95 olduğu görülmektedir. Önerilen VGG-19 mimarisine sahip CNN tabanlı derin öğrenme modelinin tüm katlar için ortalama doğruluk, kesinlik, geri çağırma ve F1-skoru değerleri sırasıyla \%97.8, \%97.6, \%97.7 ve \%97.6 olarak ölçülmüştür. Ayrıca, modelin "DR yok" vakalarını teşhis etmede \%100 başarı gösterdiği dikkati çekmektedir. Önerilen model, "Hafif NPDR" vakalarını teşhis etmede \%97.9, "Orta NPDR" vakalarını teşhis etmede \%97.4, "Şiddetli NPDR" vakalarını teşhis etmede \%97.3 ve "PDR" vakalarını teşhis etmede \%96.9 performans göstermiştir. Şekil 10-13 ve Tablo 1-4 birlikte değerlendirildiğinde, önerilen modelin hafif NPDR vakalarını diğer üç modele kıyasla üstün bir performansla sınıflandırdığ görülmektedir. Hafif NPDR vakalarını \%97.9 başarı ile sınıflandıran modelin alanında uzman hekimlerce bu evre için teşhis konulmasında oldukça etkili olduğu açıkça görülmektedir. 
Avrupa Bilim ve Teknoloji Dergisi

Tablo 1. DR Teşhisi ve Sinıflandırması için Önerilen Modelin Performansı

\begin{tabular}{|l|l|c|c|c|c|}
\hline \multicolumn{2}{|c|}{ Model/Kat } & $\begin{array}{c}\text { Acc } \\
(\%)\end{array}$ & $\begin{array}{c}\text { Prec } \\
(\%)\end{array}$ & $\begin{array}{c}\text { Rec } \\
(\%)\end{array}$ & $\begin{array}{c}\text { F1-skoru } \\
(\%)\end{array}$ \\
\hline \multirow{4}{*}{ Kat 1 } & 98.0 & 97.8 & 98.7 & 98.0 \\
\cline { 2 - 6 } & Kat 2 & 96.6 & 96.4 & 96.4 & 96.2 \\
\cline { 2 - 6 } & Kat 3 & 98.0 & 98.0 & 98.0 & 98.0 \\
\cline { 2 - 6 } & Kat 4 & 97.7 & 97.4 & 97.6 & 97.4 \\
\cline { 2 - 6 } & Kat 5 & 96.9 & 96.6 & 97.0 & 96.8 \\
\cline { 2 - 6 } & Kat 6 & 98.2 & 98.0 & 98.0 & 98.0 \\
\cline { 2 - 6 } & Kat 7 & 98.3 & 98.2 & 98.0 & 98.2 \\
\cline { 2 - 6 } & Kat 8 & 97.6 & 97.4 & 97.6 & 97.6 \\
\cline { 2 - 6 } & Kat 9 & 97.7 & 97.6 & 97.6 & 97.6 \\
\cline { 2 - 6 } & Kat 10 & 98.2 & 98.2 & 98.2 & 98.0 \\
\cline { 2 - 6 } & Ortalama & $\mathbf{9 7 . 8}$ & $\mathbf{9 7 . 6}$ & $\mathbf{9 7 . 7}$ & $\mathbf{9 7 . 6}$ \\
\hline
\end{tabular}

Tablo 2. DR Teşhisi ve Sinıflandırması için Xception Modelinin Performansı

\begin{tabular}{|l|l|c|c|c|c|}
\hline \multicolumn{2}{|c|}{ Model/Kat } & $\begin{array}{c}\text { Acc } \\
(\%)\end{array}$ & $\begin{array}{c}\text { Prec } \\
(\%)\end{array}$ & $\begin{array}{c}\text { Rec } \\
(\%)\end{array}$ & $\begin{array}{c}\text { F1-skoru } \\
(\%)\end{array}$ \\
\hline \multirow{4}{*}{} & Kat 1 & 94.4 & 94.4 & 94.4 & 94.4 \\
\cline { 2 - 6 } & Kat 2 & 94.8 & 94.6 & 94.6 & 94.4 \\
\cline { 2 - 6 } & Kat 3 & 94.4 & 94.2 & 94.2 & 94.4 \\
\cline { 2 - 6 } & Kat 4 & 95.8 & 95.6 & 95.6 & 95.6 \\
\cline { 2 - 6 } & Kat 5 & 96.7 & 96.4 & 96.6 & 96.4 \\
\cline { 2 - 6 } Kception & Kat 6 & 95.6 & 95.6 & 95.2 & 95.2 \\
\cline { 2 - 6 } & Kat 7 & 95.6 & 95.4 & 95.4 & 95.4 \\
\cline { 2 - 6 } & Kat 8 & 95.6 & 95.4 & 95.4 & 95.2 \\
\cline { 2 - 6 } & Kat 9 & 95.7 & 95.4 & 95.6 & 95.4 \\
\cline { 2 - 6 } & Kat 10 & 95.2 & 95.2 & 94.8 & 95.0 \\
\cline { 2 - 6 } & Ortalama & 95.4 & 95.2 & 95.2 & 95.1 \\
\hline
\end{tabular}


European Journal of Science and Technology

Tablo 3. DR Teşhisi ve Sınıflandırması için InceptionV3 Modelinin Performansı

\begin{tabular}{|l|l|c|c|c|c|}
\hline \multicolumn{2}{|l|}{} & $\begin{array}{c}\text { Acc } \\
(\%)\end{array}$ & $\begin{array}{c}\text { Prec } \\
(\%)\end{array}$ & $\begin{array}{c}\text { Rec } \\
(\%)\end{array}$ & $\begin{array}{c}\text { F1-skoru } \\
(\%)\end{array}$ \\
\hline \multirow{4}{*}{ Model/Kat } & Kat 1 & 89.1 & 89.0 & 88.8 & 88.8 \\
\cline { 2 - 6 } & Kat 2 & 88.7 & 88.2 & 88.6 & 88.4 \\
\cline { 2 - 6 } & Kat 3 & 88.8 & 88.4 & 88.2 & 88.2 \\
\cline { 2 - 6 } & Kat 4 & 89.3 & 89.0 & 89.0 & 88.8 \\
\cline { 2 - 6 } & Kat 5 & 87.3 & 87.0 & 87.0 & 86,8 \\
\cline { 2 - 6 } & Kat 6 & 89.0 & 88.6 & 88.6 & 88,4 \\
\cline { 2 - 6 } & Kat 7 & 89.0 & 88.6 & 89.0 & 88.6 \\
\cline { 2 - 6 } & Kat 8 & 87.4 & 87.2 & 87.6 & 87.0 \\
\cline { 2 - 6 } & Kat 9 & 89.3 & 89.0 & 88.6 & 89.0 \\
\cline { 2 - 6 } & Kat 10 & 86.9 & 86.6 & 87.0 & 86.6 \\
\cline { 2 - 6 } & Ortalama & 88.5 & 88.2 & 88.2 & 88.1 \\
\hline
\end{tabular}

Tablo 4. DR Teşhisi ve Sınıflandırması için ResNet101 Modelinin Performansı

\begin{tabular}{|l|l|c|c|c|c|}
\hline \multicolumn{2}{|c|}{ Model/Kat } & $\begin{array}{c}\text { Acc } \\
(\%)\end{array}$ & $\begin{array}{c}\text { Prec } \\
(\%)\end{array}$ & $\begin{array}{c}\text { Rec } \\
(\%)\end{array}$ & $\begin{array}{c}\text { F1-skoru } \\
(\%)\end{array}$ \\
\hline \multirow{4}{*}{ Kat 1 } & 83.8 & 83.2 & 83.4 & 83.4 \\
\cline { 2 - 6 } & Kat 2 & 84.9 & 84.8 & 84.6 & 84.4 \\
\cline { 2 - 6 } & Kat 3 & 83.7 & 83.2 & 83.4 & 83.2 \\
\cline { 2 - 6 } & Kat 4 & 84.2 & 83.8 & 83.8 & 84.0 \\
\cline { 2 - 6 } & Kat 5 & 84.7 & 84.0 & 84.2 & 84.2 \\
\cline { 2 - 6 } & Kat 6 & 85.0 & 84.6 & 84.4 & 84.4 \\
\cline { 2 - 6 } & Kat 7 & 86.1 & 86.0 & 85.8 & 85.6 \\
\cline { 2 - 6 } & Kat 8 & 85.8 & 85.2 & 85.4 & 85.4 \\
\cline { 2 - 6 } & Kat 9 & 85.2 & 85.0 & 84.6 & 84.6 \\
\cline { 2 - 6 } & Kat 10 & 85.6 & 85.2 & 85.2 & 85.2 \\
\cline { 2 - 6 } & Ortalama & 84.9 & 84.5 & 84.5 & 84.4 \\
\hline
\end{tabular}




\section{Sonuçlar ve Gelecekteki Çalışmalar}

Gözün retina ağ tabakasında yer alan kan damarlarında diyabete bağlı oluşan hasarlanmalar olarak tanımlanan DR hastalığının erken aşamada teşhisi ve tedavisi hastaların görme yetilerini kaybetmelerinin önüne geçilebilmesi için hayati önem taşımaktadır. Bu çalışmada, DR hastalığının "DR Yok, Hafif NPDR, Orta NPDR, Şiddetli NPDR ve PDR" şeklinde sınıflandırılarak erken aşamada teşhis ve tedavisi için retina görüntülerinden oluşan fundus veri seti kullanılmış ve VGG-19 mimarisine sahip CNN tabanlı derin öğrenme modeli geliştirilmiştir. Geliştirilen model hem doğruluk hem de sağlamlık parametreleri dikkate alınarak test edilmiştir. DR hastalığının sınıflandırılması için önerilen modelin doğruluk, kesinlik, geri çağırma ve F1-skoru değerleri sırasıyla \%97.8, \%97.6, \%97.7 ve \%97.6 olarak ölçülmüştür. Önerilen modelin başarımı, performans metrikleri dikkate alınarak Xception, InceptionV3 ve ResNet101 model başarımları ile kıyaslanmıştır. Elde edilen sonuçlar, DR hastalığının teşhisi için önerilen modelin belirtilen diğer modellere kıyasla oldukça yüksek sınıflandırma başarımına sahip olduğunu ortaya koymaktadır. Ayrıca, önerilen model ile özellikle DR hastalığının "Hafif NPDR" evresi diğer modellere kıyasla yüksek doğrulukla sınıflandırılmıştır. Gelecekteki çalışmalarda, DR sınıflandırma modelinin doğruluğunun ve dayanıklılığının iyileştirilebilmesi için model parametreleri metasezgisel optimizayon algoritmaları ile kestirilen melez model yapıları üzerinde çalışılacaktır. Oluşturulacak melez sınıflandırma modelleri ile belirsizlikler ve doğrusal olmayan dinamiklerle baş edilebilmesi hedeflenmektedir.

\section{Teşekkür}

Bu çalışma, Zonguldak Bülent Ecevit Üniversitesi tarafından (BAP Proje No: 2021-75737790-03) desteklenmiştir. Desteklerinden dolayı Zonguldak Bülent Ecevit Üniversitesi'ne teşekkür ederiz.

\section{Kaynakça}

APTOS (2019). Blindness detection. URL: https://www.kaggle. com/c/aptos2019-blindness-detection.

Aiello, L. M. (2003). Perspectives on diabetic retinopathy. American Journal of Ophthalmology, 136(1), 122-135.

Antcliff, R. J., Stanford, M. R., Chauhan, D. S., Graham, E. M., Spalton, D. J., Shilling, J. S., \& Marshall, J. (2000). Comparison between optical coherence tomography and fundus fluorescein angiography for the detection of cystoid macular edema in patients with uveitis. Ophthalmology, 107(3), 593-599.

Chakraborty, S., Jana, G. C., Kumari, D., \& Swetapadma, A. (2020). An improved method using supervised learning technique for diabetic retinopathy detection. International Journal of Information Technology, 12(2), 473-477.

Chan, T. H., Jia, K., Gao, S., Lu, J., Zeng, Z., \& Ma, Y. (2015). PCANet: A simple deep learning baseline for image classification. IEEE Transactions on Image Processing, 24(12), 5017-5032.

Chollet, F. (2017). Xception: Deep learning with depthwise separable convolutions. In Proceedings of the IEEE
Conference on Computer Vision and Pattern Recognition, $1251-1258$.

Deepa, V., Kumar, C. S., \& Andrews, S. S. (2021). Fusing dualtree quaternion wavelet transform and local mesh based features for grading of diabetic retinopathy using extreme learning machine classifier. International Journal of Imaging Systems and Technology, 31, 1625-1637.

Dhakal, A., Bastola, L. P., \& Shakya, S. (2019). Detection and classification of diabetic retinopathy using adaptive boosting and artificial neural network. International Journal of Advanced Research and Publications, 3(8), 191-196.

Gayathri, S., Gopi, V. P., \& Palanisamy, P. (2020). A lightweight CNN for Diabetic Retinopathy classification from fundus images. Biomedical Signal Processing and Control, 62, 102115, 1-11.

Grossniklaus, H. E., Geisert, E. E., \& Nickerson, J. M. (2015). Introduction to the retina. Progress in Molecular Biology and Translational Science, 134, 383-396.

Han, D., Liu, Q., \& Fan, W. (2018). A new image classification method using CNN transfer learning and web data augmentation. Expert Systems with Applications, 95, 43-56.

He, K., Zhang, X., Ren, S., \& Sun, J. (2016). Deep residual learning for image recognition. In Proceedings of the IEEE Conference on Computer Vision and Pattern Recognition, 770-778.

Hood, D. C., Raza, A. S., de Moraes, C. G. V., Liebmann, J. M., \& Ritch, R. (2013). Glaucomatous damage of the macula. Progress in Retinal and Eye Research, 32, 1-21.

Hossin, M., \& Sulaiman, M. N. (2015). A review on evaluation metrics for data classification evaluations. International Journal of Data Mining \& Knowledge Management Process, $5(2), 1-11$.

Indolia, S., Goswami, A. K., Mishra, S. P., \& Asopa, P. (2018). Conceptual understanding of convolutional neural network-a deep learning approach. Procedia Computer Science, 132, 679-688.

İnan, S. (2014). Retina anatomisi. Kocatepe T1p Dergisi, 15(3), 355-359.

Khan, S., Islam, N., Jan, Z., Din, I. U., \& Rodrigues, J. J. C. (2019). A novel deep learning based framework for the detection and classification of breast cancer using transfer learning. Pattern Recognition Letters, 125, 1-6.

Khan, M. A., Balgi, A. P., Chaithra, C., \& Kumar, P. (2020). Diabetic retinopathy detection by image processing algorithms and machine learning technique. JNNCE Journal of Engineering \& Management, 4(1), 8-16.

Klein Kobrin, B. E. (2007). Overview of epidemiologic studies of diabetic retinopathy. Ophthalmic Epidemiology, 14(4), 179183.

Kramer, C. K., Rodrigues, T. C., Canani, L. H., Gross, J. L., \& Azevedo, M. J. (2011). Diabetic retinopathy predicts allcause mortality and cardiovascular events in both type 1 and 2 diabetes: meta-analysis of observational studies. Diabetes Care, 34(5), 1238-1244. 
La Cour, M., \& Friis, J. (2002). Macular holes: classification, epidemiology, natural history and treatment. Acta Ophthalmologica Scandinavica, 80(6), 579-587.

Math, L., \& Fatima, R. (2021). Adaptive machine learning classification for diabetic retinopathy. Multimedia Tools and Applications, 80(4), 5173-5186.

Nazir, T., Irtaza, A., Shabbir, Z., Javed, A., Akram, U., \& Mahmood, M. T. (2019). Diabetic retinopathy detection through novel tetragonal local octa patterns and extreme learning machines. Artificial Intelligence in Medicine, 99, $101695,1-10$

Nida, N., Irtaza, A., Javed, A., Yousaf, M. H., \& Mahmood, M. T. (2019). Melanoma lesion detection and segmentation using deep region based convolutional neural network and fuzzy Cmeans clustering. International Journal of Medical Informatics, 124, 37-48.

Qummar, S., Khan, F. G., Shah, S., Khan, A., Shamshirband, S., Rehman, Z. U., Iftikhar, A. K, \& Jadoon, W. (2019). A deep learning ensemble approach for diabetic retinopathy detection. IEEE Access, 7, 150530-150539.

Russakovsky, O., Deng, J., Su, H., Krause, J., Satheesh, S., Ma, S., Huang, Z., Karpathy, A., Khosla, A., Bernstein, M., Berg, A. C., \& Fei-Fei, L. (2015). Imagenet large scale visual recognition challenge. International Journal of Computer Vision, 115(3), 211-252.

Saeedi, P., Petersohn, I., Salpea, P., Malanda, B., Karuranga, S., Unwin, N., Colagiuri, S., Guariguata, L., Motala, A. A., Ogurtsova, K., Shaw, J. E., Bright, D., Williams, R., \& IDF Diabetes Atlas Committee. (2019). Global and regional diabetes prevalence estimates for 2019 and projections for 2030 and 2045: results from the international diabetes federation diabetes atlas. Diabetes Research and Clinical Practice, 157, 107843, 1-10.

Simonyan, K., \& Zisserman, A. (2014). Very deep convolutional networks for large-scale image recognition. arXiv preprint arXiv:1409.1556, 1-14.

Stratton, I. M., Kohner, E. M., Aldington, S. J., Turner, R. C., Holman, R. R., Manley, S. E., \& Matthews, D. R. (2001). UKPDS 50: risk factors for incidence and progression of retinopathy in Type II diabetes over 6 years from diagnosis. Diabetologia, 44(2), 156-163.

Szegedy, C., Vanhoucke, V., Ioffe, S., Shlens, J., \& Wojna, Z. (2016). Rethinking the inception architecture for computer vision. In Proceedings of the IEEE Conference on Computer Vision and Pattern Recognition, 2818-2826.

Şentürk, Z. K. (2020). Artificial neural networks based decision support system for the detection of diabetic retinopathy. Sakarya Üniversitesi Fen Bilimleri Enstitüsü Dergisi, 24(2), 424-431.

Vijayan, T., Sangeetha, M., Kumaravel, A., \& Karthik, B. (2020). Gabor filter and machine learning based diabetic retinopathy analysis and detection. Microprocessors and Microsystems, 103353, 1-8.

Willoughby, C. E., Ponzin, D., Ferrari, S., Lobo, A., Landau, K., \& Omidi, Y. (2010). Anatomy and physiology of the human eye: effects of mucopolysaccharidoses disease on structure and function-a review. Clinical \& Experimental Ophthalmology, 38, 2-11. 